Research Article

\title{
Building Information Modelling- (BIM-) Based Generative Design for Drywall Installation Planning in Prefabricated Construction
}

\author{
Jose Daniel Cuellar Lobo, ${ }^{1}$ Zhen Lei $\mathbb{D}^{1},{ }^{1}$ Hexu Liu $\mathbb{D},{ }^{2}$ Hong Xian Li $\mathbb{D}^{3},{ }^{3}$ and \\ SangHyeok Han ${ }^{4}$ \\ ${ }^{1}$ Department of Civil Engineering, University of New Brunswick, Fredericton, NB E3B 5A3, Canada \\ ${ }^{2}$ Department of Civil and Construction Engineering, Western Michigan University, Kalamazoo 49008-5316, MI, USA \\ ${ }^{3}$ School of Architecture \& Built Environment, Deakin University, Geelong 3220, Australia \\ ${ }^{4}$ Department of Building, Civil, and Environmental Engineering, Concordia University, Montreal H3G 1M8, Canada
}

Correspondence should be addressed to Zhen Lei; zhen.lei@unb.ca

Received 15 December 2020; Revised 2 April 2021; Accepted 7 June 2021; Published 14 July 2021

Academic Editor: Payam Shafigh

Copyright ( $\odot 2021$ Jose Daniel Cuellar Lobo et al. This is an open access article distributed under the Creative Commons Attribution License, which permits unrestricted use, distribution, and reproduction in any medium, provided the original work is properly cited.

In prefabricated construction, building components are manufactured off-site before shipping to the site for installation. Accurate design and planning are essential for smooth on-site execution and improved efficiency, which requires evaluations of various design options. However, due to the design process's complexity, such evaluations cannot be achieved without automation and optimization. Meanwhile, the recent advancement of digital design technologies (e.g., building information modelling (BIM)) has enabled flexibility in the design process. The integration of BIM with other analytical algorithms also allows optimization of designs, such as the generative design that can parametrize the design. This study proposes a generative design approach that utilizes the optimization of the drywall installation layout to improve overall project efficiency. The framework includes a decision support module that considers environmental, cost, and aesthetic aspects to identify the optimal layout. The framework's practical applicability has been successfully demonstrated through a case study. After implementation, three "best" design alternatives were found according to the decision aspects. The design improvements achieved were $37.5 \%, 7 \%$, and $54 \%$ for the environmental, cost, and aesthetic factors, respectively. Accordingly, practitioners can make better decisions on planning drywall projects. This approach has proven effective in planning drywall installation and can be applied in similar design scenarios for other prefabricated construction processes.

\section{Introduction}

The prefabricated construction approach has been widely adopted to improve construction efficiency and productivity. Compared to the traditional stick-built construction process, prefabrication takes a manufacturing style to produce building components off-site and ship them to the installation site. Prefabrication has been applied in various construction sectors, e.g., residential, commercial, and heavy industrial construction. In the prefabrication design process, the structural and architectural design information is converted into shop drawings for manufacturing and on-site installation instructions. In the North American housing industry, residential houses are often constructed using wood products. Wood panels are manufactured in the factory environment and shipped to the site for installation. In such a process, the wall panels' interior and external faces are covered with sheathing made of materials such as gypsum and plywood. Sheathing materials come in standard sizes, and their installation often involves cutting the material into smaller pieces, generating scrap waste. Such waste has negative economic and environmental impacts due to the high cost of processing waste, levied in part as a landfill tax [1]. However, prefabricated construction provides opportunities to improve the sheathing installation practice. Plans for sheathing layout can be generated before 
installation in a more controlled work environment. Therefore, there is a research potential to develop a BIMbased approach to optimize the sheathing layout arrangement in a prefabricated construction environment.

BIM has been widely used in the construction industry to improve design and planning (i.e., estimating and scheduling) and project management efficiencies [2]. For example, BIM was used for quantifying construction components (e.g., volumes) in managing the high-rise walls [3]. Application programming interfaces (APIs) were utilized to develop BIM tools to achieve automated scheduling systems for facility management [4]. As BIM-related technologies evolved, BIM is often integrated with other emerging technologies to solve construction design and coordination issues. For instance, reality capture, including 3D scanning, was recently introduced in the construction industry to enhance site surveying and ensure design accuracy [5]. A study has been conducted to explore the benefits of incorporating $3 \mathrm{D}$ scanning with BIM to achieve quantity management with accuracy and efficiency [6]. Another area of emerging technologies in BIM is to utilize immersive environments (e.g., virtual reality and mixed reality) to visualize and coordinate the design concepts. This can enable the users to better understand the design ideas, visualize the planned construction activities, and mitigate unnecessary risks/safety hazards [7-9]. However, in the prefabricated construction industry, the available BIM platforms in the construction market are designed for general purposes and not meant for prefabricated construction processes. Accordingly, designers also need to incorporate design criteria such as manufacture, logistics, and assembly processes [10]. Efforts have been made to automate and improve the construction design in the BIM environment. For example, a methodology to generate prefabricated shop drawings from BIM 3D models was proposed for automation on a production line to reduce waste [11-15]. Parametric modelling allows users to control the design using input parameters, such as concrete joint layout design using dynamo, an opensource visual programming language [16]. A similar application is to use BIM to achieve roof sheathing layout optimization [1]. As BIM-related technologies have been developed, the design information from BIM can be incorporated into other analytical purposes in prefabrication, e.g., (1) enhanced manufacturing process and product evaluation in prefabrication [17-19], (2) BIM-enabled decision support tools (e.g., Internet of Things and radio frequency identification) in the prefabrication supply chain $[6,20-24]$, and (3) improvement of productivity and efficiency in the prefabrication processes [3, 25-27].

In parallel with the development of BIM technologies, a generative design (GD) has been developed as an iterative design process that relies on computer calculations to generate a certain number of design options that meet the design constraints. In such practice, the design process is often parametrized, and by altering such design parameters, the design output can improve its performance through evaluations [28]. In construction, generative design is often seen integrated with BIM technologies. For example, design checks can be performed through generative design, which increases the design efficiencies compared to the manual design evaluation processes $[29,30]$. This technique can be adopted in mass production environments, where similar design products are repetitively produced [28].

This research proposes a BIM-based GD approach to optimize the sheathing layout arrangement in a prefabricated construction environment. This approach can allow practitioners to reduce the overall waste for given designs and evaluate various layout alternatives. The proposed model has been developed and implemented in a Python environment. A script has been created in the dynamo environment to visualize the optimized layouts in the BIM platform. A fuzzy analytical hierarchy process (AHP) methodology is implemented to prioritize management criteria and select the best layout option accordingly.

\section{Methodology}

Figure 1 shows the overall research methodology, consisting of four analytical modules and one visualization module: (1) the geometrical information of building components (i.e., the wall frame geometric coordinates) is extracted from the BIM 3D model. (2) Such information is entered into a simulation-based design algorithm. Cost-related data are also used as inputs to the model, such as material prices and unit labour costs. The simulation algorithm incorporates the design and installation rules to generate multiple feasible design alternatives for the drywall layout. (3) A heuristic optimization approach is used to locally optimize the material waste of each design alternative by using a greedy algorithm. (4) A fuzzy AHP methodology is introduced to rank the design alternatives and select the best option according to the prioritization of management criteria. (5) The results are returned to a computational BIM software, i.e., Dynamo, for visualization in the BIM environment. Each step will be further explained in the following subsections.

2.1. Data Extraction. In this research project, the information from BIM models consists of the geometric properties (i.e., coordinates) and the material properties (i.e., type of material). BIM models may also contain information about construction management such as unit material costs and unit labour costs which are commonly used at the planning stage of a construction project. In the implementation, the BIM information is extracted from a Revit model for woodframe structures. However, the process of data extraction can be generalized for other model types. In this particular research study, the BIM model information is exported as an $\mathrm{XML}$ file, which is then used as inputs for the simulation process. Another part of the data inputs is the cost information of material and labour. In the construction industry, such cost information can be collected from material supply vendors. In this research project, the authors have used sample cost information from the market and labour rate in the local Canadian construction industry (Table 1). 


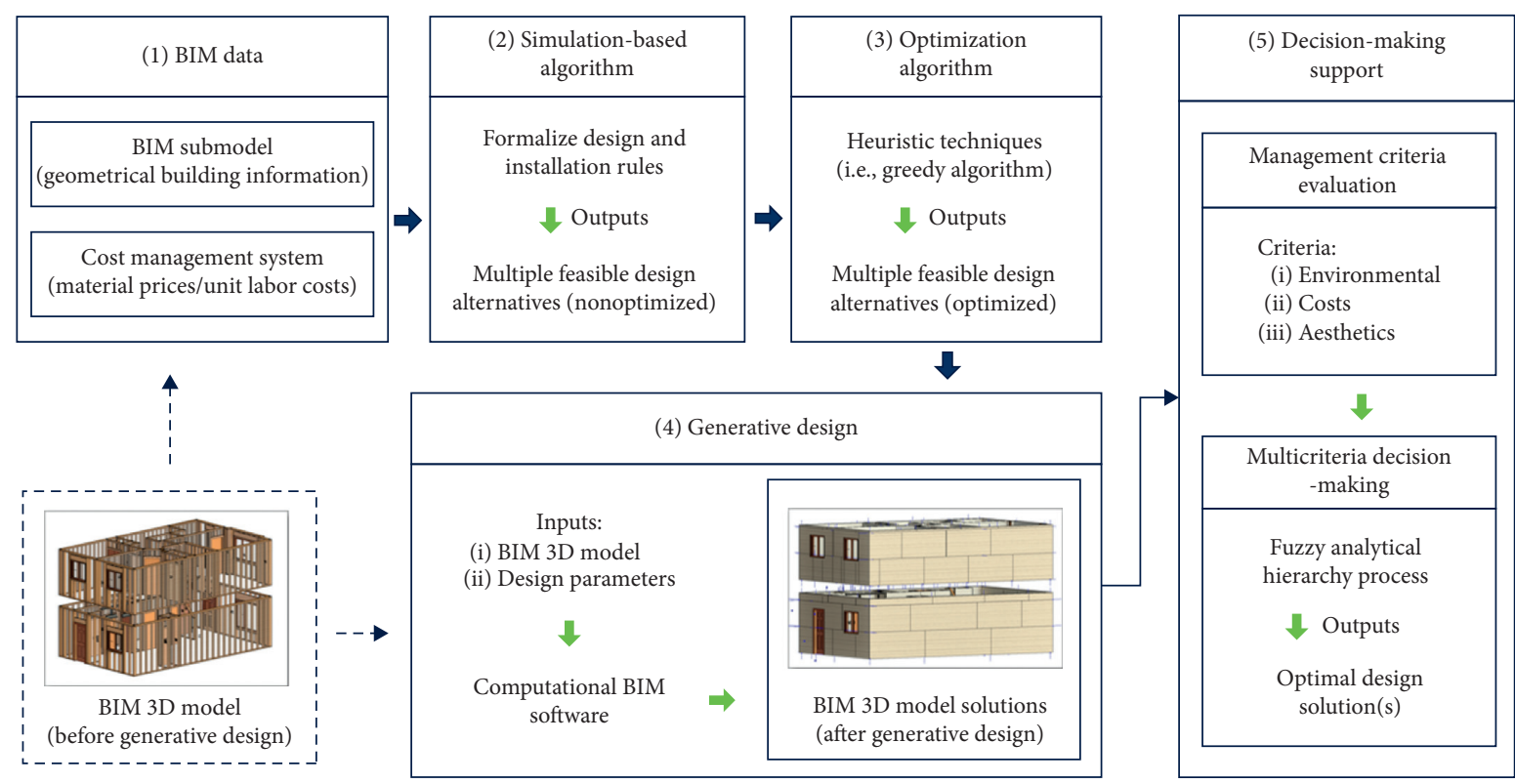

Figure 1: Overall methodology.

TABLE 1: Sample cost information for drywall material and productivity in Canadian construction market.

\begin{tabular}{|c|c|c|c|}
\hline & Cost/price & Units & Source \\
\hline \multicolumn{4}{|l|}{ Drywall materials } \\
\hline $\begin{array}{l}\text { CGC sheetrock } 1 / 2 \text { in } \times 4 \mathrm{ft} . \times 8 \mathrm{ft} \text {. } \\
\text { ultralight drywall panel }\end{array}$ & $\$ 13$ & $\$ C A D /$ unit & http://www.homedepot.ca \\
\hline $\begin{array}{l}\text { CGC sheetrock } 1 / 2 \text { in } \times 4 \mathrm{ft} . \times 10 \mathrm{ft} \text {. } \\
\text { ultralight drywall panel }\end{array}$ & $\$ 16$ & $\$ C A D /$ unit & http://www.homedepot.ca \\
\hline $\begin{array}{l}\text { CGC sheetrock } 1 / 2 \text { in } \times 4 \mathrm{ft} . \times 12 \mathrm{ft} \text {. } \\
\text { ultralight drywall panel }\end{array}$ & $\$ 19$ & $\$ C A D /$ unit & http://www.homedepot.ca \\
\hline \multicolumn{4}{|c|}{ Drywall installation (measuring/cutting/nailing) } \\
\hline $\begin{array}{l}\text { Productivity }=60 \text { sq. ft./hr (crew: } 2 \\
\text { people) }\end{array}$ & $\$ 50$ & $\$ \mathrm{CAD} / \mathrm{hr}$ & Industry partner \\
\hline \multicolumn{4}{|l|}{ Drywall finishing (mudding/taping) } \\
\hline $\begin{array}{l}\text { Productivity = } 50 \text { Lin. ft./hr (crew: } 2 \\
\text { people) }\end{array}$ & $\$ 70$ & $\$ \mathrm{CAD} / \mathrm{hr}$ & Industry partner \\
\hline \multicolumn{4}{|l|}{ Waste processing costs } \\
\hline Landfill tipping fee in NB & $\$ 28$ & $\$ C A D /$ tonne & $\begin{array}{l}\text { https://www.fundyrecycles.com/solid_waste/ } \\
\text { crane_mountain_landfill/construction_and_demolition/ }\end{array}$ \\
\hline $\begin{array}{l}1 / 2 \text { in. ultralight Drywall panel weight } \\
\text { about } 1.25 \mathrm{lb} / \mathrm{sq} . \mathrm{ft} \text {. }\end{array}$ & & $\begin{array}{l}1 \text { tonne }=2204.62 \\
\mathrm{lb}\end{array}$ & https://drywall101.com/en/articles/hanging/weight_of_drywall \\
\hline $\begin{array}{l}\text { CGC sheetrock } 1 / 2 \text { in. } \times 4 \mathrm{ft} . \times 8 \mathrm{ft} \text {. } \\
\text { ultralight drywall panel }\end{array}$ & $\$ 0.51$ & $\$ C A D /$ unit & Calculated \\
\hline $\begin{array}{l}\text { CGC sheetrock } 1 / 2 \text { in } \times 4 \mathrm{ft} . \times 10 \mathrm{ft} \text {. } \\
\text { ultralight drywall panel }\end{array}$ & $\$ 0.64$ & $\$ C A D /$ unit & Calculated \\
\hline $\begin{array}{l}\text { CGC sheetrock } 1 / 2 \text { in } \times 4 \mathrm{ft} . \times 12 \mathrm{ft} \text {. } \\
\text { ultralight drywall panel }\end{array}$ & $\$ 0.76$ & $\$ C A D /$ unit & Calculated \\
\hline
\end{tabular}

2.2. Simulation-Based Design Algorithm. The generative design takes parameterized design inputs to generate design alternatives for later evaluation purposes. Upon data extraction, the simulation algorithm takes the data inputs and runs loops for alternative design generation. Figure 2 shows a high-level logic flowchart for the simulation loops. The process starts by initializing the simulation cycles. The simulation loop generates a random factor as the starting point for generating the design alternatives. Following that, the simulation checks the design rules as specified by the users. The case study section for specific design rules in implementation is given in the following. If the design alternative satisfies the design rules, then it is entered into an optimization algorithm for minimizing the material waste (this will be further elaborated in the following section). Last, the design alternative's results are stored in each simulation cycle 


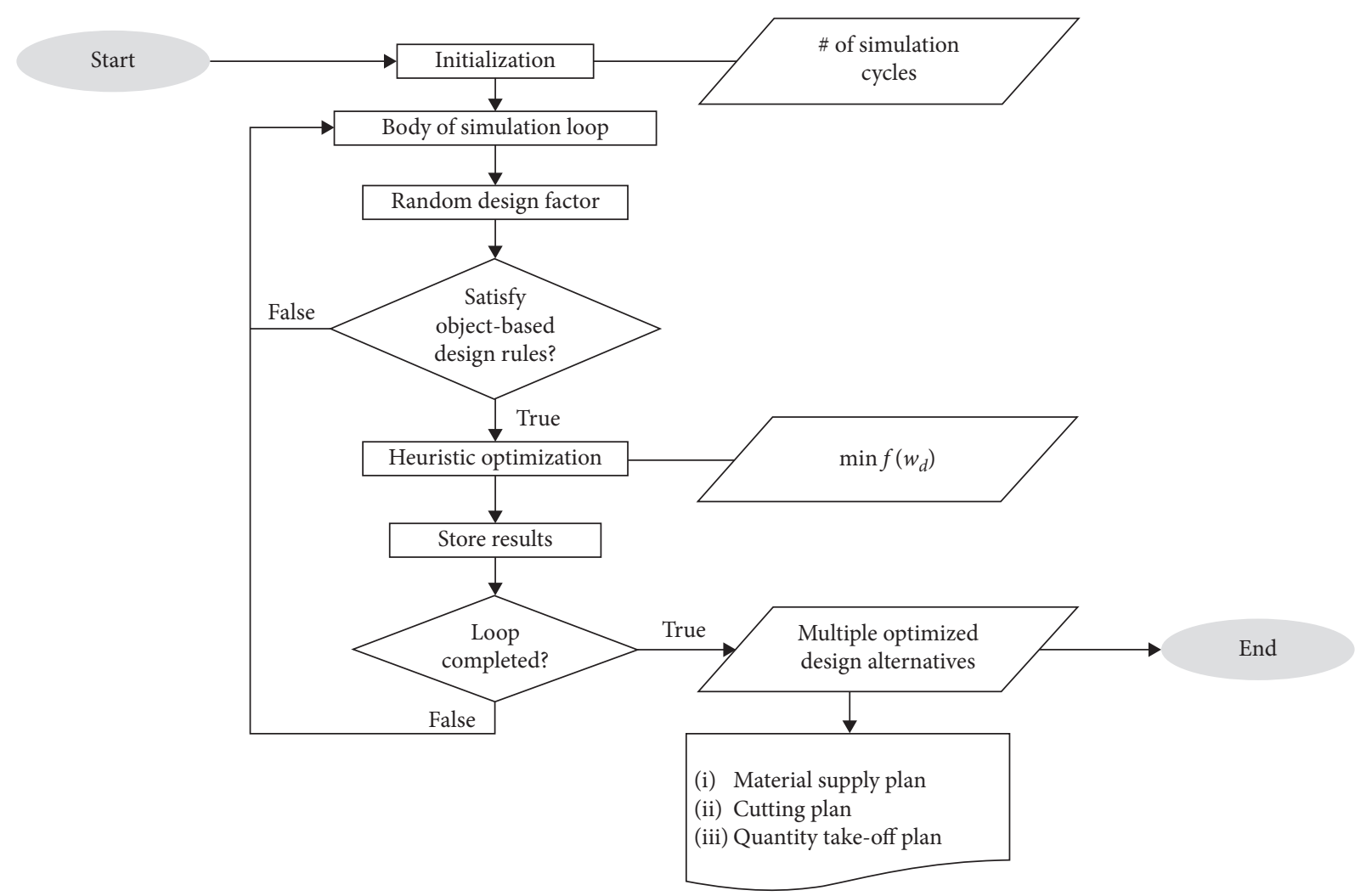

Figure 2: High-level logic flowchart for the simulation and optimization algorithm.

until all iterations are completed. The outputs include multiple layouts which are locally optimized in terms of material waste. A purchase material plan, a cutting plan, and a quantity take-off plan are provided in the simulation's outcomes. Such alternatives will be further evaluated through the decisionmarking support (module four in Figure 1).

2.3. Heuristic Optimization Algorithm. As mentioned above (Figure 2), after the design rules are checked and satisfied, the heuristic algorithm attempts to reduce the material waste in each design alternative locally. Accordingly, the algorithm reuses drywall cuts in the design layout, wall by wall, following a set of heuristic rules (Figure 3). The heuristic optimization objective function is formulated as follows:

\section{Minimize}

$$
\begin{gathered}
\min f\left(w_{d}\right) \quad d=1, \ldots, n \\
w_{d}=\sum_{i=1}^{x} S_{i, d}-\sum_{j=1}^{y} M_{i, d},
\end{gathered}
$$

subject to

$$
g_{m}\left(w_{d}\right)>b_{m}, \quad m=1, \ldots, n,
$$

where $w_{d}$ denotes the material waste associated with the design alternative $d, d$ is the index of a design alternative in a list of $n$ design alternatives, $S_{i, d}$ denotes the size of each material stock $i$ in each design alternative $d$ in a given unit of measurement (i.e., square feet), $x$ is the number of drywall stock material, $M_{i, d}$ denotes the area of each drywall material used in each design alternative $d, y$ is the number of drywall pieces used in the layout, and $g_{m\left(w_{d}\right)}$ represents the constraints to the optimization. In this case, design parameters (e.g., the length of drywall cuts reused in the layouts) are incorporated to constrain the heuristic optimization algorithm. $b_{m}$ are the boundaries or numerical values that constrain such parameters.

2.4. Decision-Making Support. Module four ("Decisionmaking support" in Figure 1) intends to evaluate all the design alternatives generated by the simulation-based optimization algorithm. This module consists of two steps: (1) assessing the design layouts under three management criteria: environmental, cost, and aesthetic aspects, and (2) implementing a fuzzy AHP methodology to rank the design alternatives to identify the optimal design alternative(s) according to the prioritization of management criteria. In the first step, the mentioned aspects are quantified and calculated as follows:

(1) Environmental criterion: used to assess the environmental impact of material waste by calculating the material waste percentage of each design alternative, as formulized as

$$
\mathrm{WP}_{d}=\frac{\mathrm{WA}_{d}}{\mathrm{SA}_{d}} * 100
$$



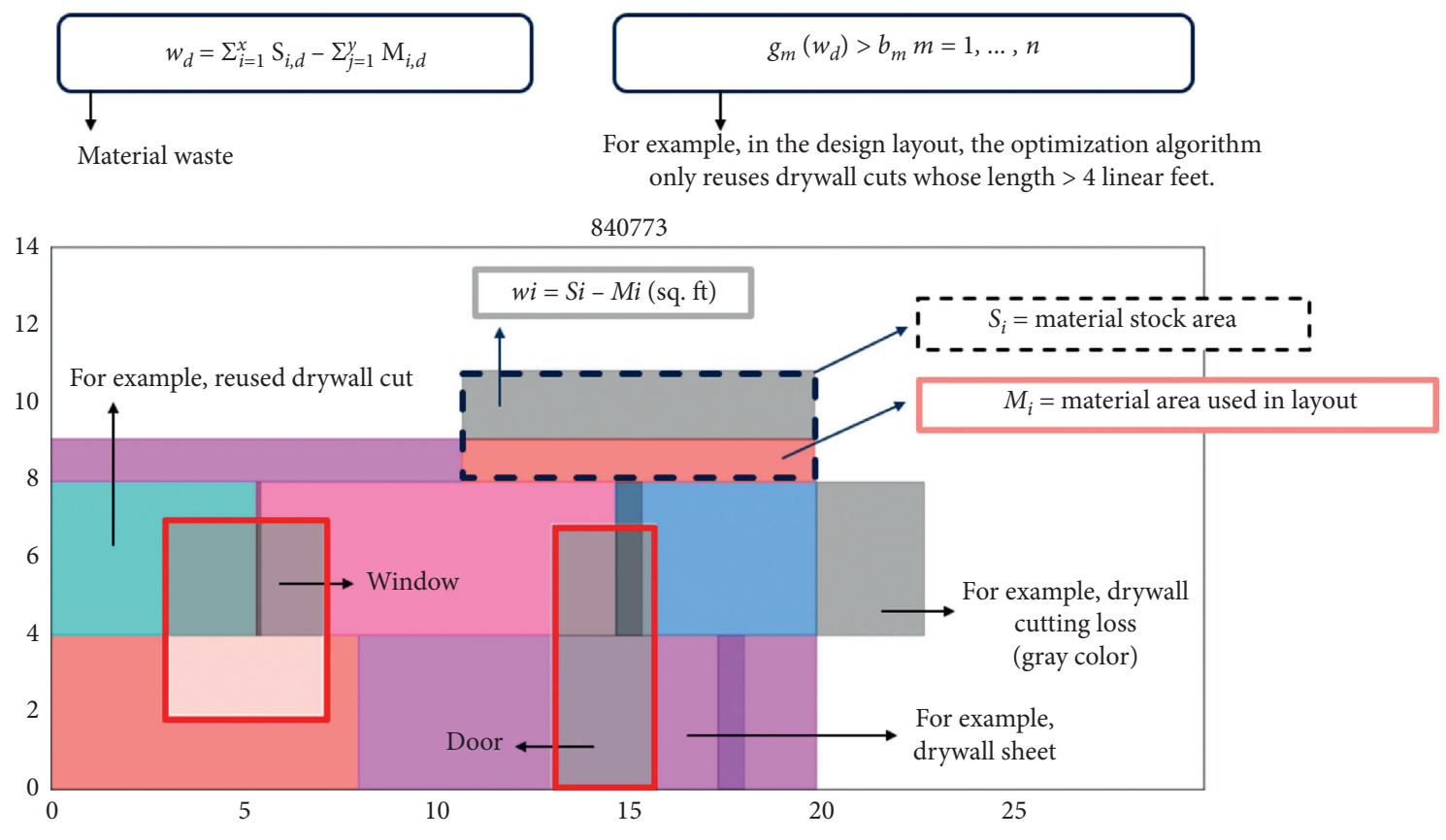

FIGURE 3: Illustration to explain the parameters involved in equations (1)-(3).

where $\mathrm{WP}_{d}$ is the material waste percentage of each design alternative $d, \mathrm{WA}_{d}$ denotes the areas associated with the waste material, and $\mathrm{SA}_{d}$ represents the areas related to the total stock material.

(2) Cost criterion: used as an indicator of the costs associated with the drywall operation, categorized into three components: the material, installation, and waste processing costs, as calculated using the following formula:

$$
\begin{aligned}
C_{d} & =\mathrm{MC}_{d}+\mathrm{IC}_{d}+\mathrm{WC}_{d}, \\
\mathrm{MC}_{d} & =\sum_{i=1}^{x} \mathrm{SA}_{i, d} \times \mathrm{SUC}_{i, d}, \\
\mathrm{IC}_{d} & =\sum_{i=1}^{y} \frac{\mathrm{SA}_{i, d} * \mathrm{ULC}_{i, d}}{P_{i, d}}, \\
\mathrm{WC}_{d} & =\mathrm{WA}_{d} * \mathrm{LFC}_{d},
\end{aligned}
$$

where $C_{d}$ is the total cost of each design alternative, $\mathrm{MC}_{d}$ is the material cost, $\mathrm{IC}_{d}$ is the material installation cost, $\mathrm{WC}_{d}$ is the waste processing cost, $\mathrm{SA}_{i, d}$ is the stock material area, $\mathrm{SUC}_{i, d}$ is the stock unit cost, $\mathrm{ULC}_{i, d}$ is the unit labour cost, $P_{i, d}$ is the productivity of material installation, $\mathrm{WA}_{d}$ is the material waste area, and $\mathrm{LFC}_{d}$ is the landfill processing cost. The cost data used in this research to estimate the total costs associated with the case of study are presented in Table 1.

(3) Aesthetic criterion: the drywall joints' total length in each design scenario is the factor selected to quantify the aesthetic component of the layouts. Accordingly, the total length of the joints is calculated by the following formula:

$$
J_{d}=\sum_{i=1}^{z} \mathrm{JL}_{d},
$$

where $J_{d}$ is the total length of the joints among drywall pieces in each design alternatived, $\mathrm{JL}_{d}$ denotes the individual length of each joint, and $z$ represents the number of drywall joints.

Following the calculation of the management criteria, the fuzzy AHP is used to rank the design alternatives. The fuzzy AHP is a multicriteria decision-making technique based on AHP, which incorporates the decision-makers' uncertainty using fuzzy numbers (range of values) [31]. Thus, fuzzy AHP is proposed instead of a traditional AHP, which is criticized for its inability to deal with imprecision and subjectivity associated with the decision-makers' judgment [31-34]. In this research, triangular fuzzy numbers are used because of their computational simplicity and ability to represent fuzzy environments. A triangular fuzzy number can be denoted as $A=(a 1, a 2, a 3)$ [35]. The fuzzy AHP uses a comparison scale of relative importance to construct a comparison matrix by making pairwise comparisons of selected criteria (Table 2 for the fuzzy fundamental scale of relative importance) [32, 36, 37]. After constructing the comparison matrix, probability (priority weight) is calculated for each criterion that determines the likelihood of achieving the decision-makers' expected goal, relatively compared with its corresponding criteria. In this research, the numerical ratings are obtained through interviews with domain experts (e.g., construction project managers and material suppliers). 
TABLE 2: AHP and fuzzy AHP scales of relative importance.

\begin{tabular}{lcccc}
\hline \multirow{2}{*}{ Scale } & \multicolumn{2}{c}{ AHP Saaty scale } & \multicolumn{2}{c}{ Fuzzy triangular scale } \\
& Numerical rating & Reciprocal & Numerical rating & Reciprocal \\
\hline Extremely preferred & 9 & $1 / 9$ & $(8,9,10)$ & $(1 / 10,1 / 9,1 / 8)$ \\
Very strongly preferred & 7 & $1 / 7$ & $(6,7,8)$ & $(1 / 8,1 / 7,1 / 6)$ \\
Strongly preferred & 5 & $1 / 5$ & $(4,5,6)$ & $(1 / 6,1 / 5,1 / 4)$ \\
Moderately preferred & 3 & $1 / 3$ & $(2,3,4)$ & $(1 / 4,1 / 3,1 / 2)$ \\
Equally preferred & 1 & 1 & $(1,1,1)$ & $(1,1,1)$ \\
\hline
\end{tabular}

The numerical rating of the relative importance is then used to calculate the fuzzy AHP final score by multiplying it with the selected criterion (environmental, cost, and aesthetic). The design alternative with the highest value of the fuzzy AHP final score yields the optimal design option. This can be expressed as the following formula:

$$
\text { Optimal design }=\max \left\{\sum \mathrm{NR}_{i, j} \times \mathrm{FAHP}_{i, j}\right\}
$$

where $\mathrm{NR}_{i, j}$ is the numerical rating associated with each criterion, and $\mathrm{FAHP}_{i, j}$ denotes the fuzzy AHP priority weight of each criterion.

\section{Implementation and Case Study}

In this research, a two-story wood residential house (53 wood frames) is used as a case study to demonstrate the development. Figure 4 shows the developed 3D model (only shows the wood frames) in the Revit environment. The design information (e.g., coordinates of wood frame components) is extracted from the BIM environment into XML files through a script developed in the Revit software. Methods of developing the code for BIM information extraction can be found in the previous work [38]. The BIM data inputs needed for the simulation model include geometrical information, dimensions, and properties of building objects such as walls, floors, doors, windows, and studs (Figure 5).

3.1. General Simulation Implementation Logic. Once the data are extracted into the Python environment, simulation cycles will be initiated to generate drywall layouts following the logic presented in Figure 6: (1) thirty simulation cycles are initiated for this layout generation process, based on different drywall sizes (e.g., nominal size $4 \times 8$ or $4 \times 10$ drywall sheets). (2) The body of the simulation loop consists of a "for loop" to iterate through each simulation cycle. Generally, the algorithm loops wall by wall in each simulation cycle to place the drywall sheets of different nominal sizes (randomly) accordingly. The system will retrieve each wall information, determine wall orientation, and plot drywall rows for the layouts based on the predefined design rules (following section details the design rule descriptions). (3) The system then uses the cutting losses (material waste from drywall sheet cutting) for optimization. The optimization algorithm is presented in Figure 7. Accordingly, design layouts are created and optimized for all the walls in the BIM 3D model, and the process is repeated in each simulation cycle to generate different design possibilities. (4) The optimized results are eventually entered into the fuzzy AHP analysis after optimization and simulation loops are completed.

In the layout generation, the considered design rules are as follows. (1) Vertical or horizontal orientation: if the length of a drywall sheet is greater than the height of a wall and the height of the drywall sheet is greater than the length of the wall, then the drywall sheet is placed in a vertical orientation (Figure 8). Otherwise, the drywall sheet is placed in a horizontal direction. (2) Sequence: if drywall sheets are determined to be placed in a horizontal orientation, each row in the wall represents a sequence of drywall sheets placed horizontally. For example, if the height of the drywall sheets is $4 \mathrm{ft}$. and the height of the wall is $8 \mathrm{ft}$., then the drywall design layout in the wall will constitute two horizontal rows. (3) Drywall edge on stud: drywall edges must be aligned with a stud to be nailed against the wall. Else, the drywall sheet must be cut, so that its edge is correctly aligned with a stud. (4) Staggered seams: a gap of $1 / 8$ in. should be set as the seam space between two drywall sheets. Also, drywall seams must not be aligned in two consecutive rows in the wall to ensure the structure's better integrity. (5) Openings in doors and windows: the areas around the openings of doors and windows are of high stress. Thus, drywall seams should be placed away from such locations to avoid cracks of seams. Figure 9 aims to provide clarification for the design rules (2), (3), (4), and (5). Additional details and explanations to general drywall design and installation rules can be found in the previous work [38].

Figure 7 shows the optimization algorithm that refers to the "heuristic optimization: greedy algorithm" in Figure 6. The greedy algorithm uses heuristic rules to prioritize the reuse of the cutting pieces based on their dimensions. First, a greedy best fit algorithm is used to verify if any of the cutting parts can be reused in the design layout without having to cut the piece again (local optimum). If such a scenario is not possible, then another greedy algorithm is used to order the list of cutting pieces according to their area. In this scenario, the local optimum is achieved by assuming that the reuse of a larger piece will result in less waste generated in the model. When optimizing the material waste, the authors considered cut piece lengths in material reuse, for example, when a piece of cutting losses (material scrap) is more than $2 \mathrm{ft}, 4 \mathrm{ft}, 6 \mathrm{ft}$, or $0 \mathrm{ft}$, then it is considered in reuse either on the same wall or 


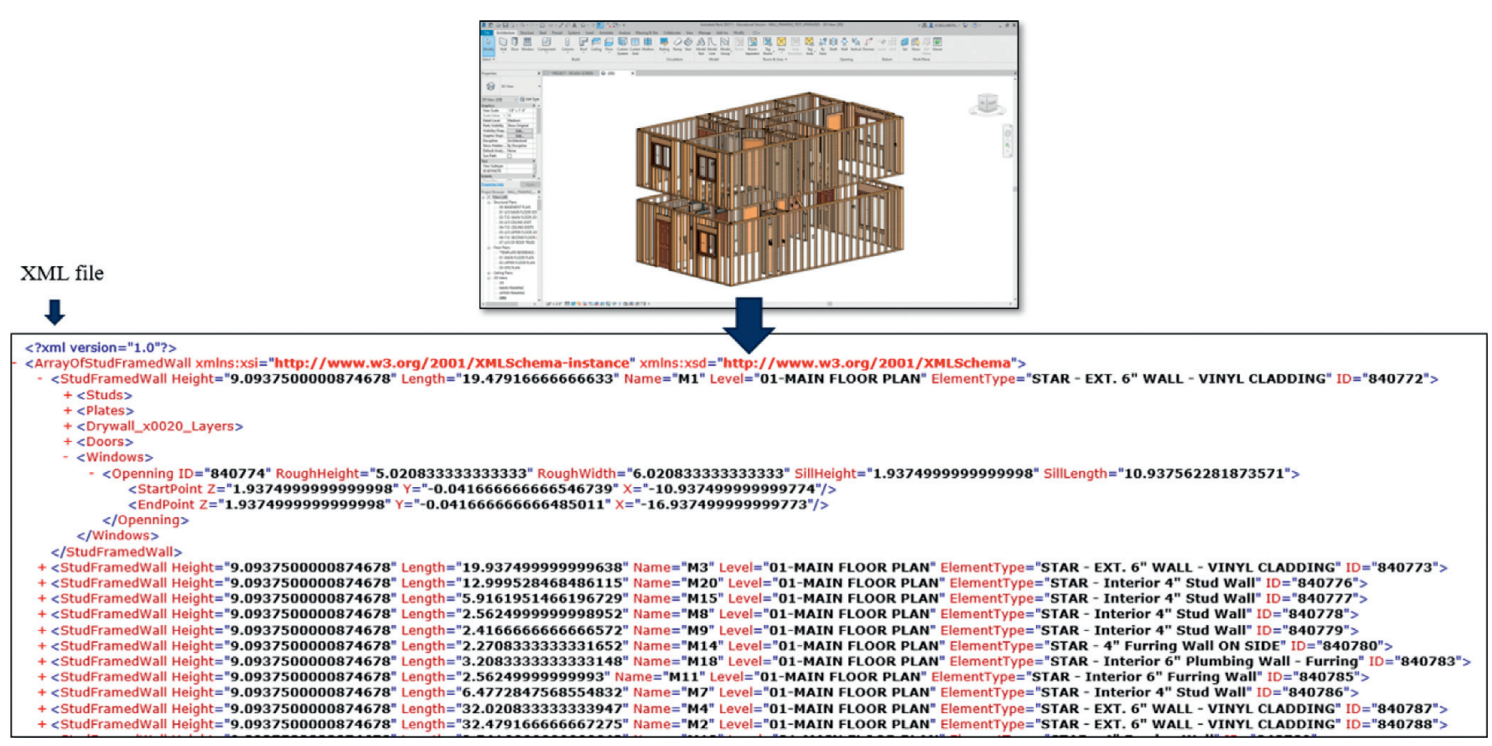

Figure 4: Wood framed residential house case.
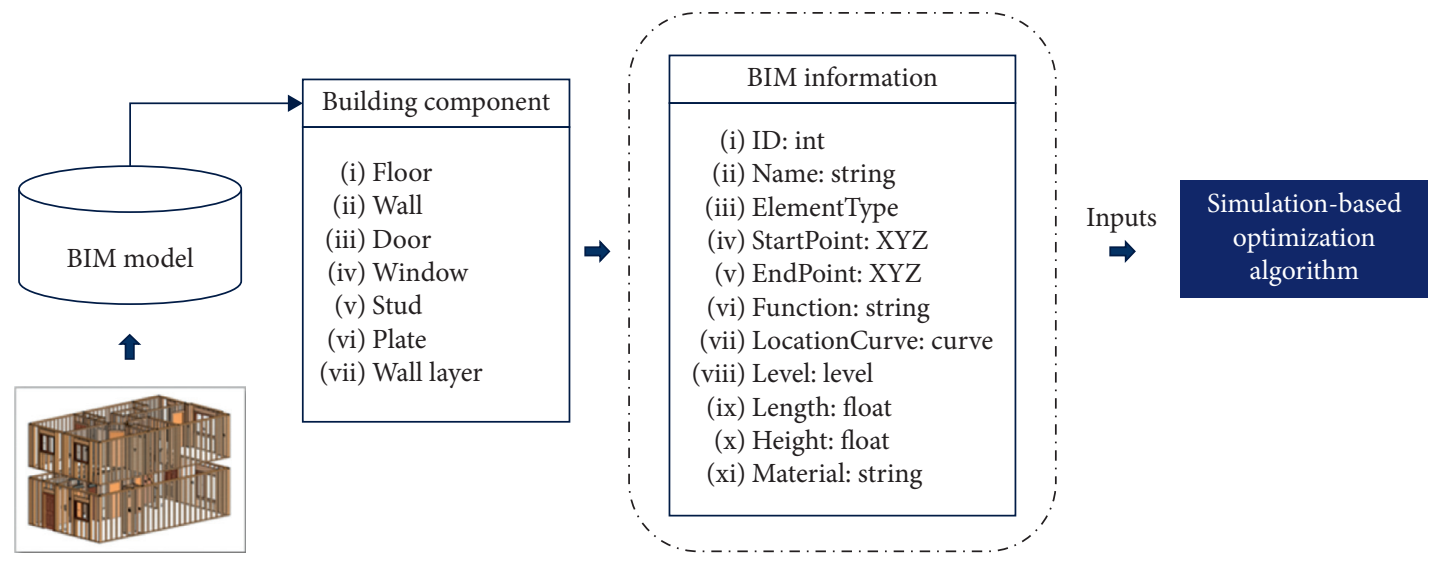

FIGURE 5: Diagram of building elements and attributes associated with the BIM model [38].

other walls. Eventhough the implementation follows specific design rules as mentioned above, similar logic can be applied with modifications to other design scenarios.

\subsection{Fuzzy Analytical Hierarchy Process (AHP): Numerical} Example. The design scenarios generated by the simulation algorithm for different design parameters (e.g., cutting pieces of various dimensions) are evaluated by three criteria for improved planning using the fuzzy AHP: environmental criterion, cost criterion, and the aesthetic criterion (as discussed above in the "Methodology"). A summary of the simulation results for the given case study is presented in Figure 10. Each boxplot illustrates the maximum and minimum values according to the evaluation criteria and the interquartile range (IQR) of the simulation results. For example, the boxplot located at the left of Figure 10 shows a minimum material waste of $10 \%$ for all scenarios and median material waste close to $16 \%$. Then, a relative score is assigned to each design scenario based on the IQR of the simulation results as proposed in Figure 11 to rank the alternatives.

After all the layout options have been ranked, a fuzzy AHP comparison matrix is constructed by making pairwise comparisons of the criteria using the fuzzy scale of relative importance (Table 2 ). Table 3 provides an example of how the fuzzy comparison matrix is created after industry experts have compared each criterion. The green and yellow colours are used to represent the numerical ratings and reciprocal ratings, respectively. If the triangular fuzzy number is denoted by $A=(\mathrm{a} 1, \mathrm{a} 2, \mathrm{a} 3)$, then its reciprocal can be expressed as $A^{-1}=\left(a_{1}, a_{2}, a_{3}\right)^{-1}$ or $A^{-1}=\left(\left(1 / a_{1}\right),\left(1 / a_{2}\right),\left(1 / a_{3}\right)\right)$. Then, the fuzzy geometric mean $(r)$ is computed for each criterion using the following equation (Table 4 ).

$$
r_{i}=\left[a_{i 1} * \ldots * a_{\mathrm{in}}\right]^{1 / n},
$$

where $a_{i n}$ is a fuzzy value associated with the pairwise comparison of criterion $i$ to criterion $n$. 


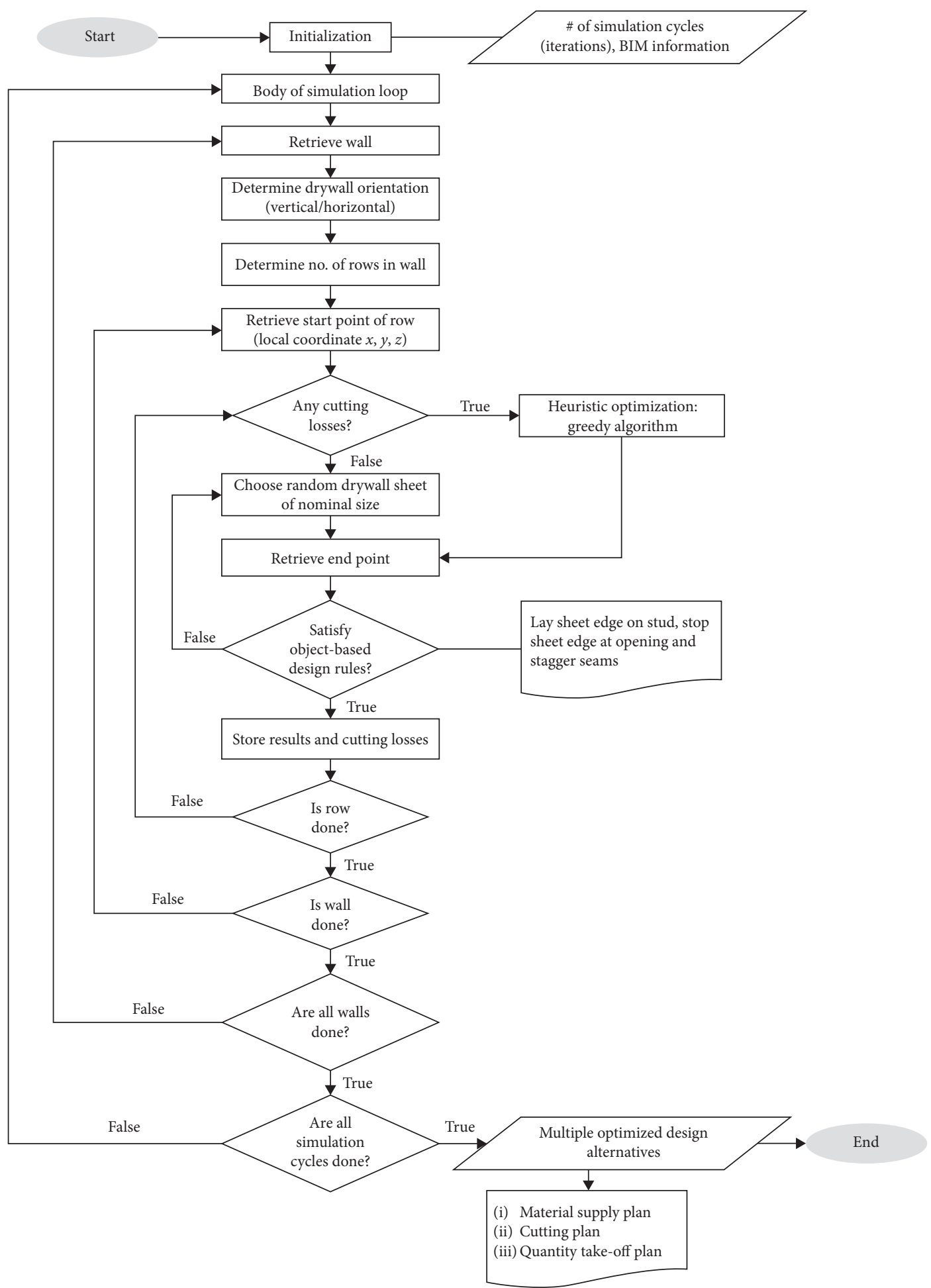

FIgURE 6: Simulation implementation logic for layout generation and evaluation.

After the fuzzy geometric mean is calculated for each criterion, fuzzy weights $w_{i}$ are computed by normalization, as shown in equation $(8) ; w_{i}$ can also be denoted as $w_{i}=$ $\left(L_{w}, M_{w}, U_{w}\right)$ as a triangular fuzzy number, where
$L_{w}, M_{w}$, and $U_{w}$ represent the lower, middle, and upper bounds of the fuzzy weight for each criterion $i$. Table 5 provides the fuzzy weights obtained for each criterion in the numerical example. 


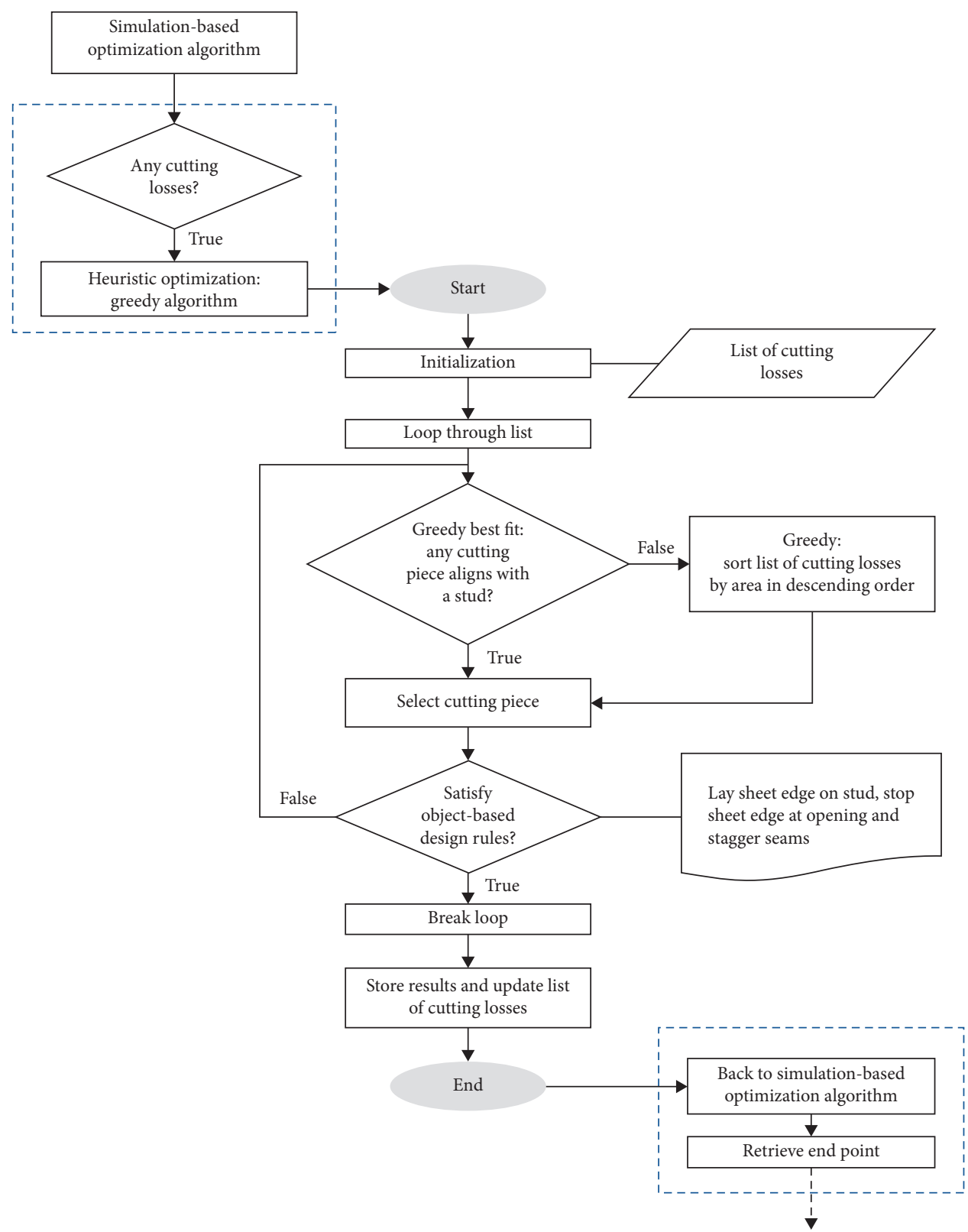

FIgURE 7: Logic for the greedy optimization algorithm.

$$
w_{i}=\left[r_{1} * \ldots * r_{n}\right]^{-1} .
$$

An average fuzzy weight (priority weight) is then calculated and normalized to determine the likelihood of achieving the decision-makers' expected goal (Table 5). In this numerical example, the aesthetic aspect is the criterion with the highest importance (i.e., fuzzy priority weight), $66 \%$, according to the fuzzy AHP technique.

Last, a final fuzzy AHP score is calculated by multiplying the fuzzy AHP priority weight with the ranked alternatives' relative score. As expressed in equation (6), the design alternative with the highest value of the fuzzy AHP final score yields the optimal design solution(s). Table 6 provides the design alternatives with the highest final fuzzy AHP score. In this example, the design layouts s 25 and s65 accounted for the best solutions according to management criteria' prioritization.

In Figure 12, two hypothetical scenarios are presented to assess the impact of the fuzzy AHP methodology. Notably, different fuzzy AHP priority weights produce different optimal design alternatives, as illustrated in Figure 12. In case 1 , the aesthetic component accounted for the highest priority weight, 66\%, which results in the following best design scenarios: s25 and s65. However, in case 2, the best design layouts are different (s62, s88, and s177) because each component's relative importance was modified. Therefore, the "best" design solution is conditional to the prioritization of management criteria. Accordingly, a set of fuzzy AHP priority weights in practice may rely upon the goals of the company or decision-makers. For example, a subcontractor 


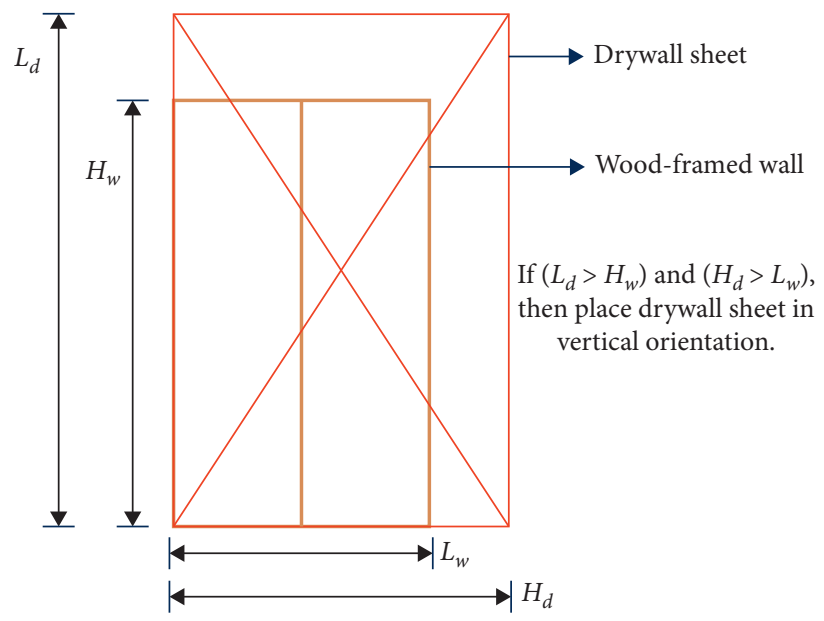

FIgURE 8: Vertical placement of drywall sheet-front elevation view [38].

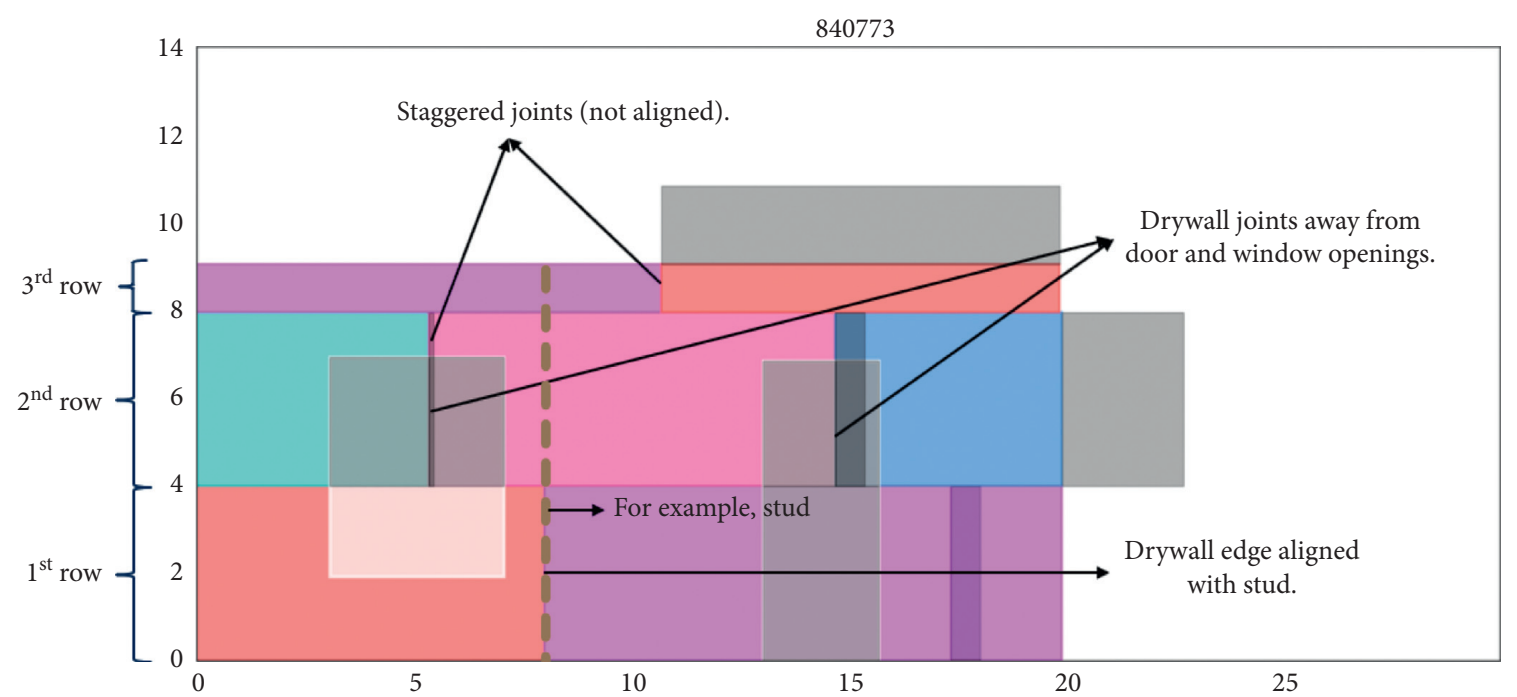

FIgURE 9: Staggered drywall sheet layout-front elevation view [38].

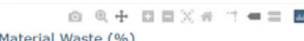

Material Waste $(\%)$

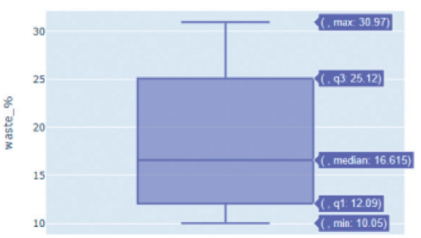

(a)

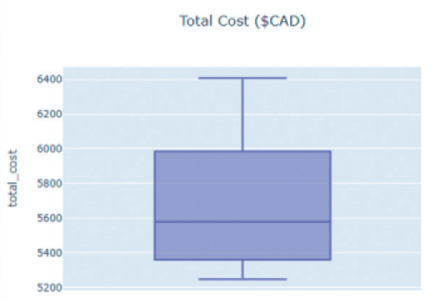

(b)
Length of Drywall Joints (lin. $f(t)$

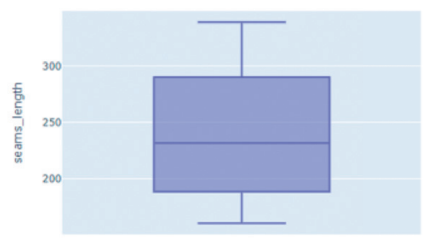

(c)

Figure 10: Simulation results classified by evaluation criteria. (a) Environmental criterion. (b) Total cost criterion. (c) Aesthetic criterion.

may only opt to minimize the overall process cost and take no notice of material waste's environmental impact. In such a case, the cost criterion would account for the highest priority weight. On the other hand, another company may consider a trade-off of the mentioned criteria, giving relative importance to each aspect according to desired goals. Thus, the fuzzy AHP technique demonstrates its value in selecting a design scenario. 


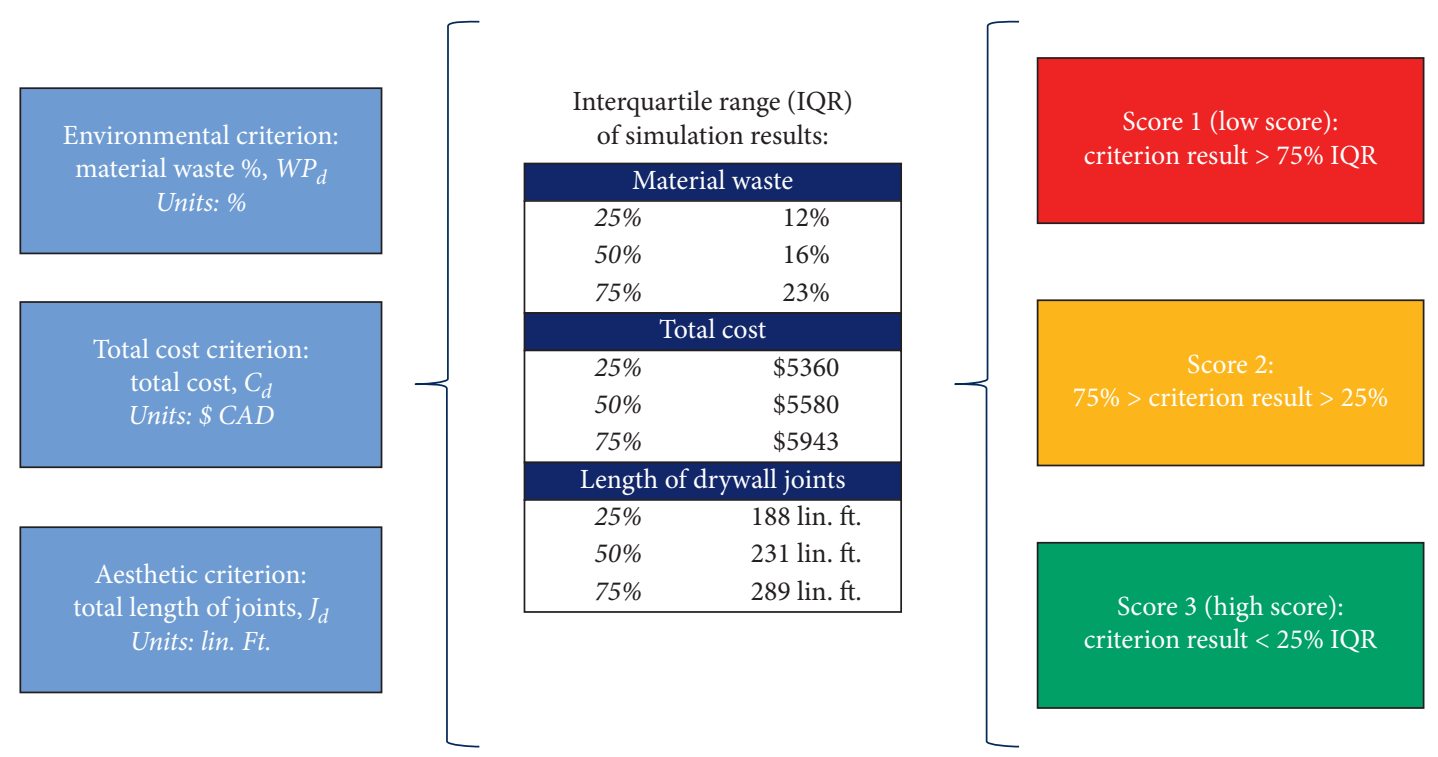

FIGURE 11: Relative scores based on IQR of the simulation results.

TABLE 3: Fuzzy pairwise comparison matrix.

\begin{tabular}{lccccccccc}
\hline Criteria & \multicolumn{3}{c}{ Aesthetic } & \multicolumn{3}{c}{ Environmental } & \multicolumn{3}{c}{$\begin{array}{c}\text { Total } \\
\text { cost }\end{array}$} \\
\hline Aesthetic & $\mathbf{1}$ & $\mathbf{1}$ & $\mathbf{1}$ & 4 & 5 & 6 & 2 & 3 & 4 \\
Environmental & 0.17 & 0.20 & 0.25 & $\mathbf{1}$ & $\mathbf{1}$ & $\mathbf{1}$ & 1 & 1 & 1 \\
Total cost & 0.25 & 0.33 & 0.50 & 1.00 & 1.00 & 1.00 & $\mathbf{1}$ & $\mathbf{1}$ & $\mathbf{1}$ \\
\hline
\end{tabular}

The bold values (1) are just used to highlight that the compared criteria are equally important (e.g., aesthetic vs. aesthetic).

TABle 4: Fuzzy geometric mean.

\begin{tabular}{ll}
\hline Criteria & Geometric mean \\
\hline Aesthetic & $(2.00,2.47,2.88)$ \\
Environmental & $(0.55,0.58,0.63)$ \\
Total cost & $(0.63,0.69,0.79)$ \\
\hline
\end{tabular}

TABLe 5: Fuzzy weights.

\begin{tabular}{lccc}
\hline Criteria & Fuzzy weight & Average weight & $\begin{array}{c}\text { Normalized } \\
\text { weight }\end{array}$ \\
\hline Aesthetic & $(0.46,0.66,0.91)$ & 0.68 & 0.66 \\
Environmental & $(0.13,0.16,0.20)$ & 0.16 & 0.16 \\
Total cost & $(0.15,0.19,0.25)$ & 0.19 & 0.19 \\
& & 1.03 & 1.00 \\
\hline
\end{tabular}

3.3. Computational Design Using Dynamo. Ultimately, the final design scenarios generated are visualized in the Revit environment by using computational design software, Dynamo. Dynamo is a visual programming tool that works with Revit and provides access to the API. The logic for the developed dynamo script is shown in Figure 13. In this research, the dynamo platform is used to incorporate the design scenarios and visualize the results with the highest weighted score after implementation of the fuzzy AHP methodology. First, the program's inputs in dynamo include all geometric coordinates and properties associated with drywall sheets and building elements. Such data are imported from an Excel file where the simulation outputs are stored. Next, a Revit software function, namely, "Divide Parts," is used to create a graphical representation of the drywall sheets placed against each wall panel in the Revit 3D model. In Revit, drywall elements are created as "Wall Layers," meaning that the geometric dimensions of the drywall elements will resemble the dimensions of the wall elements. For example, if a wall element has a height of 10 linear feet (lin. ft.) and a length of 20 lin. ft., then the drywall element will have the same dimensions as the wall in the Revit model (Figure 14). Due to this default Revit configuration, the drywall element is designated as a "part" in the 3D model and that "part" can be divided into smaller parts by sketching division lines. As previously mentioned, drywall sheets are usually manufactured in the construction industry in nominal sizes of $4^{\prime} \times 8^{\prime}, 4^{\prime} \times 10^{\prime}$, and $4^{\prime} \times 12^{\prime}$; on account of this, the Revit API function "Divide Parts" is used to recreate realistic drywall sheets' sizes in the 3D model by sketching the drywall joints as division lines. The "Divide Parts" function is enabled for each wall where drywall sheets are placed in a horizontal orientation and is activated with three parameters (i.e., attributes): the element part to be divided (drywall layer), a sketch plane as geometrical reference for each wall, and the division lines (drywall joints) which are the intersecting references to divide the selected parts. Ultimately, the final and optimal design scenarios can be visualized in the Revit environment by implementing this program in the computational design environment, dynamo, as presented in Figure 15. It is important to note that drywall layers are placed on the interior face of the walls. However, Figure 15 shows that the drywall sheets are placed on the exterior face of the wall. This graphical representation was performed intentionally by the authors for visualization purposes of the results in this research, and nonetheless, the final prototype accounts for this demand. 
TABLE 6: Final fuzzy AHP scores for the ten highest-ranked design alternatives.

\begin{tabular}{|c|c|c|c|c|c|c|c|c|}
\hline \multirow{2}{*}{ Top 10} & \multirow{2}{*}{ Scenario } & \multicolumn{3}{|c|}{ Criteria } & \multicolumn{3}{|c|}{ Score } & \multirow{2}{*}{$\begin{array}{l}\text { Final fuzzy AHP score } \\
\text { Total (weight } * \text { score) }\end{array}$} \\
\hline & & Joints (feet) & Waste (\%) & Total cost & Aesthetic & Environmental & Total cost & \\
\hline 1 & s25 & 184.4 & 20.53 & 5733.78 & 3 & 2 & 2 & 2.66 \\
\hline 2 & s65 & 185.2 & 19.96 & 5614.84 & 3 & 2 & 2 & 2.66 \\
\hline 3 & $s 62$ & 244.46 & 11.84 & 5255.77 & 2 & 3 & 3 & 2.34 \\
\hline 4 & s88 & 257.39 & 12.09 & 5274.04 & 2 & 3 & 3 & 2.34 \\
\hline 5 & s117 & 288.58 & 11.03 & 5267.43 & 2 & 3 & 3 & 2.34 \\
\hline 6 & s3 & 187.88 & 28.96 & 6220.97 & 3 & 1 & 1 & 2.31 \\
\hline 7 & s6 & 163.79 & 28.26 & 6136.44 & 3 & 1 & 1 & 2.31 \\
\hline 8 & s11 & 178.87 & 27.91 & 6157.11 & 3 & 1 & 1 & 2.31 \\
\hline 9 & s15 & 169.77 & 30.82 & 6255.28 & 3 & 1 & 1 & 2.31 \\
\hline 10 & s18 & 168.47 & 28.83 & 6173.76 & 3 & 1 & 1 & 2.31 \\
\hline
\end{tabular}
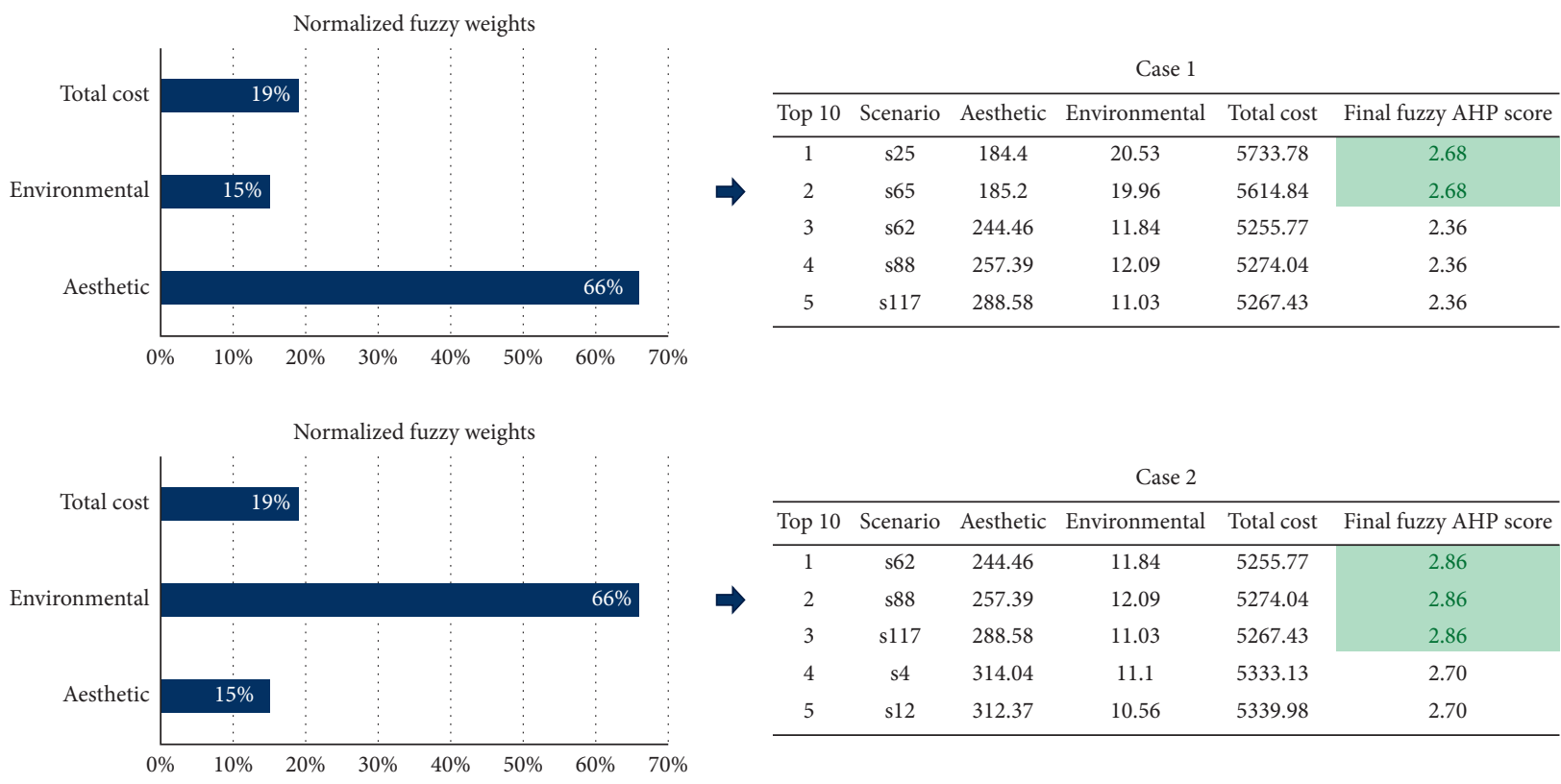

\begin{tabular}{ccccccc}
\multicolumn{7}{c}{ Case 2 } \\
\cline { 2 - 6 } Top 10 & Scenario & Aesthetic & Environmental & Total cost & Final fuzzy AHP score \\
\hline 1 & s62 & 244.46 & 11.84 & 5255.77 & 2.86 \\
2 & s88 & 257.39 & 12.09 & 5274.04 & 2.86 \\
3 & s117 & 288.58 & 11.03 & 5267.43 & 2.86 \\
4 & s4 & 314.04 & 11.1 & 5333.13 & 2.70 \\
5 & s12 & 312.37 & 10.56 & 5339.98 & 2.70 \\
\hline
\end{tabular}

Figure 12: Final results based on fuzzy AHP priority vectors.

\section{Evaluation of the Results and Discussion}

The simulation results' statistical median was the metric used to compare the scenarios against the optimal solutions (the summary of simulation results, Figure 10). Best design layout solutions were classified according to three management criteria: (1) environmental criterion: the best design layout in terms of material waste percentage achieved a $37.5 \%$ reduction compared to the simulation results' median (16\%). (2) Cost criterion: the best design layout in terms of total cost accomplished a $7 \%$ reduction compared to the simulation results' median (CAD 5,580). (3) Aesthetic criterion: the best design layout in terms of drywall seam' length achieved a 54\% reduction compared to the simulation results' median (231 lin. ft.). Previous research focused solely on reducing material waste percentage for drywall sheathing material $[1,24]$. This study results extend the previous research work by incorporating additional management criteria to the layout assessments, such as the cost and aesthetic aspects. Accordingly, this research's model achieved a minimum of $10 \%$ material waste percentage contrasted with $6.8 \%$ in the previous work [24]. However, it is important to note that the best design layout solution in this study can be a trade-off of multiple management criteria prioritization.

The results of the practical implementation highlight the advantages of the developed BIM-based generative design framework. In a traditional construction approach, exploring design possibilities is limited because it is a timeconsuming and complex task for designers [24]. However, GD allows the exploration of multiple design alternatives that vary according to different management criteria. The design nature of a layout is inherent to its planning and execution. In other words, each unique design alternative undergoes individual planning and installation tasks. Hence, the proposed framework's importance is to explore and analyze multiple design alternatives and their effect in planning and installation activities to guide practitioners to an optimal solution ultimately. 


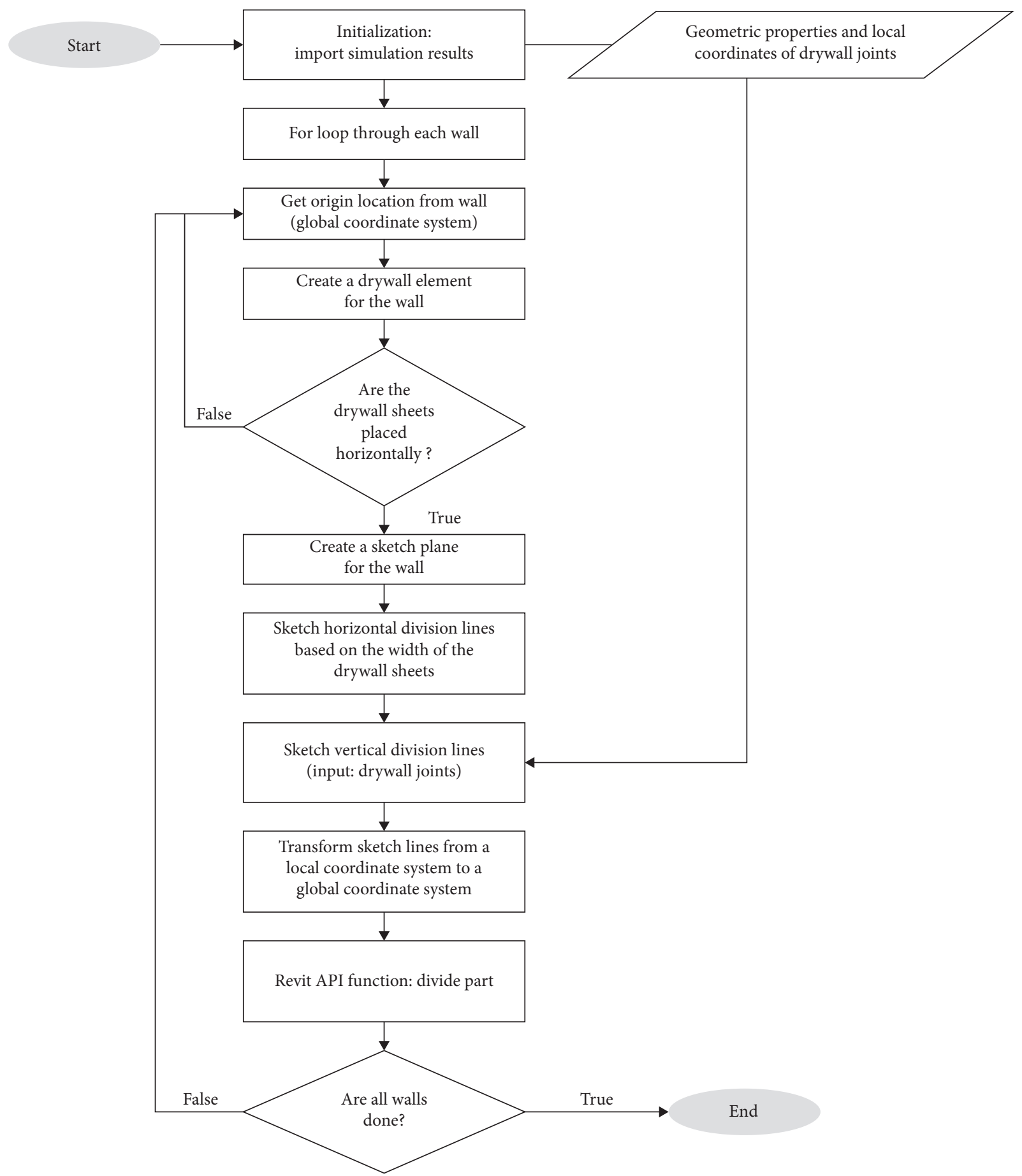

FIGURE 13: Logic for implementation of computation design. 


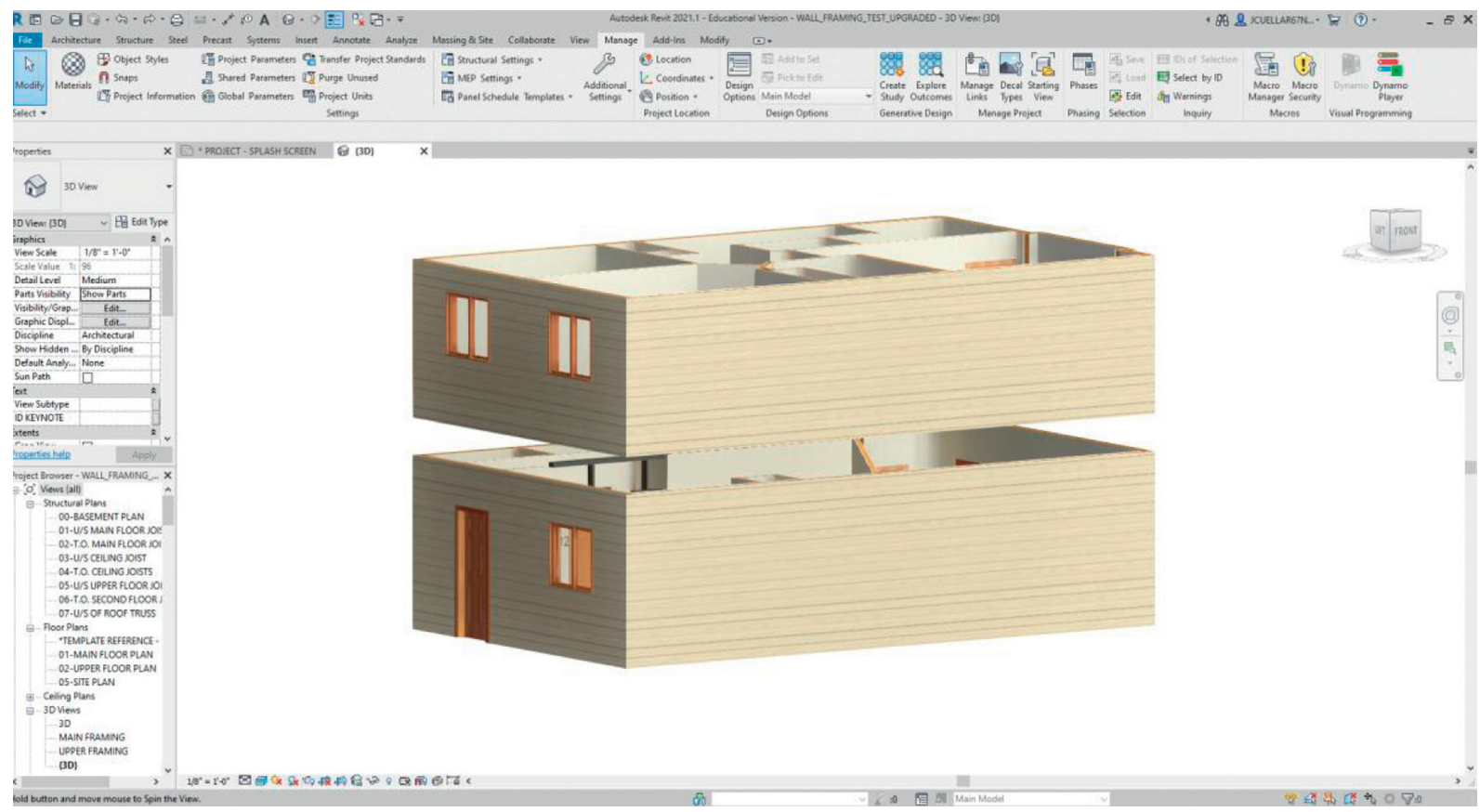

FIgURE 14: Example of the drywall elements in a Revit environment.

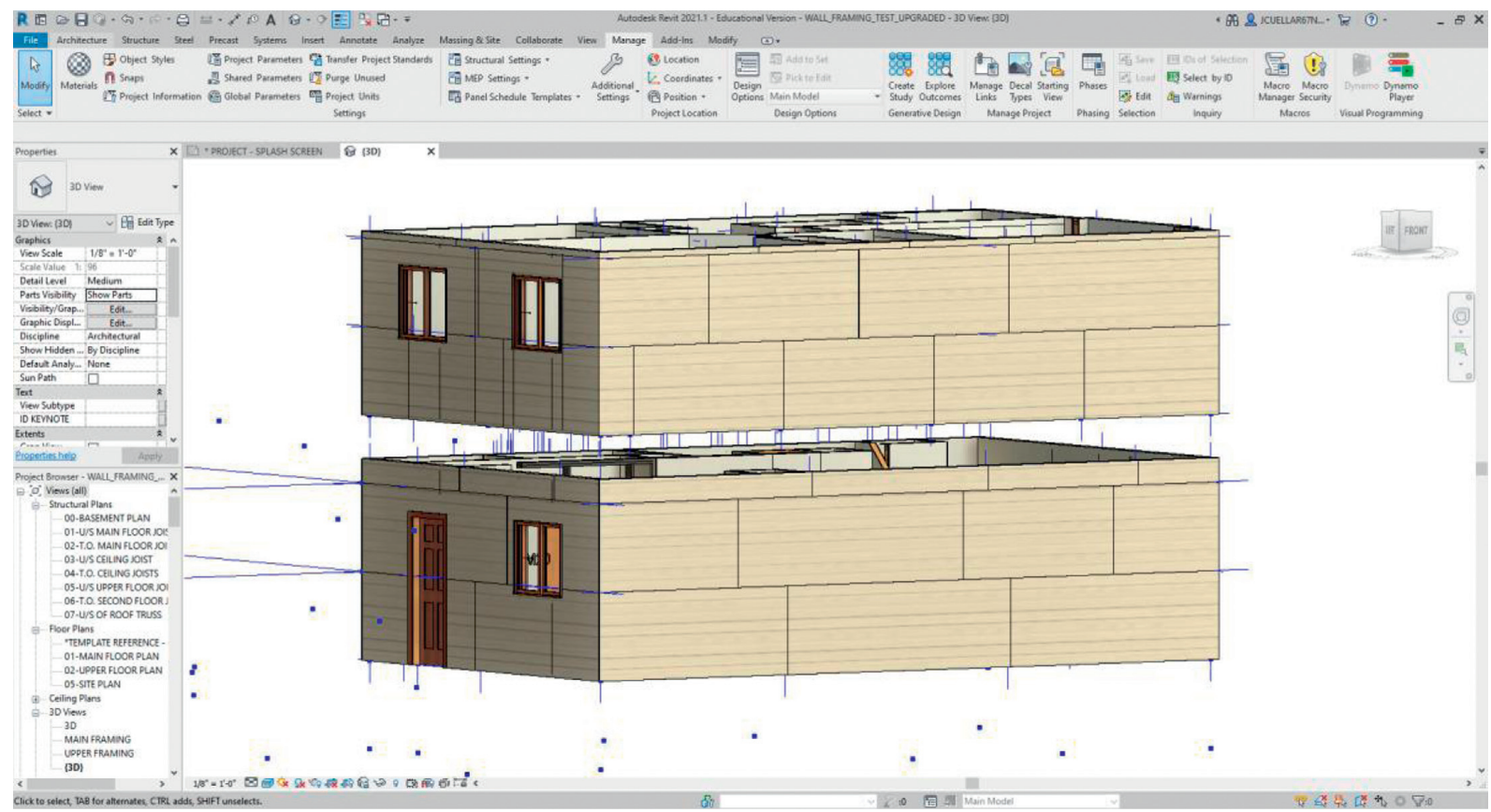

FIgURE 15: Example of the drywall layout through execution of dynamo.

\section{Conclusions}

This research has introduced a generative design approach for drywall layout design by incorporating the fuzzy AHP. The approach has been proven effective in providing drywall layouts for the prefabricated construction scenarios. The development can benefit the construction team with planning and reduce waste. The generated drywall layouts can be provided to the prefabricated construction companies (e.g., drywall installers) to precut the material before installing. This can shorten the construction schedule and reduce material waste. The research results show optimal design alternatives under three management criteria: material waste percentage (37.5\% reduction), total cost ( $7 \%$ reduction), and drywall seam' length (54\% reduction) (Figure 10). Accordingly, such best options refer to different layout alternatives according to individual assessment components. It was concluded that the "best" design layout solution is 
conditional to the prioritization of management criteria. The research contributions of this research include (1) generative design in prefabricated construction planning and design, (2) incorporation of generative design with simulation approaches to introduce randomness in results generations, and (3) implementation of the fuzzy AHP approach in generative design results evaluation.

\section{Recommendations and Future Work}

The generative design and visual programming model can be applied generically in other prefabricated construction planning scenarios. Possible future research directions can include (1) incorporating real-time field data for decisionmaking. For example, when the drywall is being installed onsite, the workers can update the productivity information to rerun the designed system and update the outputs accordingly; (2) the current development does not consider the availability of material (e.g., inventory) and constraints on logistics. The future development can fill the gap by including the supply chain into the analysis; and (3) the development can be integrated directly with BIM data exchange standards (e.g., industry foundation classes (IFC)) to enhance interoperability and compatibility. The results can be translated into machine language (e.g., CNC) to achieve automation in manufacturing and production.

\section{Data Availability}

The data used to support the findings of this study are included within the article.

\section{Conflicts of Interest}

The authors declare that they have no conflicts of interest.

\section{Acknowledgments}

The authors appreciate the funding support from the Natural Sciences and Engineering Research Council of Canada (NSERC) (ALLRP549126-19 and RGPIN-2020-04126).

\section{References}

[1] H. Liu, C. Sydora, M. S. Altaf, S. Han, and M. Al-Hussein, "Towards sustainable construction: BIM-enabled design and planning of roof sheathing installation for prefabricated buildings," Journal of Cleaner Production, vol. 235, pp. 1189-1201, 2019.

[2] A. Wahab and J. Wang, "Factors-driven comparison between BIM-based and traditional 2D quantity takeoff in construction cost estimation," Engineering Construction and Architectural Management, 2021.

[3] T. Anh Nguyen, P. Thanh Nguyen, S. Tien Do, and P. Thanh Phan, "Application of building information modelling (BIM) in managing the volume of high-rise building walls," Materials Today: Proceedings, 2021.

[4] W. Chen, K. Chen, J. C. P. Cheng, Q. Wang, and V. J. L. Gan, "BIM-based framework for automatic scheduling of facility maintenance work orders," Automation in Construction, vol. 91, pp. 15-30, 2018.
[5] H. Son and C. Kim, "Automatic segmentation and 3D modeling of pipelines into constituent parts from laser-scan data of the built environment," Automation in Construction, vol. 68, pp. 203-211, 2016.

[6] T. A. Nguyen, P. T. Nguyen, and S. T. Do, "Application of BIM and 3D laser scanning for quantity management in construction projects," Advances in Civil Engineering, vol. 2020, Article ID 8839923, 10 pages, 2020.

[7] C. Sydora, Z. Lei, M. F. F. Siu, S. Han, and U. Hermann, "Critical lifting simulation of heavy industrial construction in gaming environment," Facilities, vol. 39, no. 1/2, pp. 113-131, 2020.

[8] H. Li, G. Chan, and M. Skitmore, "Visualizing safety assessment by integrating the use of game technology," Automation in Construction, vol. 22, pp. 498-505, 2012.

[9] S. Ahn, T. Kim, Y.-J. Park, and J.-M. Kim, "Improving effectiveness of safety training at construction worksite using 3D BIM simulation," Advances in Civil Engineering, vol. 2020, Article ID 2473138, 12 pages, 2020.

[10] X. Yin, H. Liu, Y. Chen, and M. Al-Hussein, "Building information modelling for off-site construction: review and future directions," Automation in Construction, vol. 101, pp. 72-91, 2019.

[11] J. Won and J. C. P. Cheng, "Identifying potential opportunities of building information modeling for construction and demolition waste management and minimization," Automation in Construction, vol. 79, pp. 3-18, 2017.

[12] J. D. Manrique, M. Al-Hussein, A. Bouferguene, and R. Nasseri, "Automated generation of shop drawings in residential construction," Automation in Construction, vol. 55, pp. 15-24, 2015.

[13] H. Liu, B. Holmwood, C. Sydora, G. Singh, and M. AlHussein, "Optimizing multi-wall panel configuration for panelized construction using bim," in Proceedings of the 9th International Structural Engineering and Construction Conference Resilient Structures Sustainable Construction, Valencia, Spain, July 2017.

[14] M. Abushwereb, H. Liu, and M. Al-hussein, "A knowledgebased expert approach towards automated manufacturingcentric BIM: wood frame design and modelling for lightframe buildings," Modular and Offsite Construction (MOC) Summit Proceedings, pp. 1-8, 2019.

[15] R. Lu and I. Brilakis, "Digital twinning of existing reinforced concrete bridges from labelled point clusters," Automation in Construction, vol. 105, Article ID 102837, 2019.

[16] M. Sheikhkhoshkar, F. Pour Rahimian, M. H. Kaveh, M. R. Hosseini, and D. J. Edwards, "Automated planning of concrete joint layouts with 4D-BIM," Automation in Construction, vol. 107, Article ID 102943, 2019.

[17] S. An, P. Martinez, M. Al-Hussein, and R. Ahmad, "BIMbased decision support system for automated manufacturability check of wood frame assemblies," Automation in Construction, vol. 111, Article ID 103065, 2020.

[18] C. Rausch, M. Nahangi, C. Haas, and W. Liang, "Monte Carlo simulation for tolerance analysis in prefabrication and offsite construction," Automation in Construction, vol. 103, pp. 300-314, 2019.

[19] Y. Ji, K. Qi, Y. Qi et al., "BIM-based life-cycle environmental assessment of prefabricated buildings," Engineering Construction and Architectural Management, vol. 27, no. 8, pp. 1703-1725, 2020.

[20] X. Li, G. Q. Shen, P. Wu, and T. Yue, "Integrating building information modeling and prefabrication housing production," Automation in Construction, vol. 100, pp. 46-60, 2019. 
[21] C. Z. Li, F. Xue, X. Li, J. Hong, and G. Q. Shen, "An internet of things-enabled BIM platform for on-site assembly services in prefabricated construction," Automation in Construction, vol. 89, pp. 146-161, 2018.

[22] R. Bortolini, C. T. Formoso, and D. D. Viana, "Site logistics planning and control for engineer-to-order prefabricated building systems using BIM 4D modeling," Automation in Construction, vol. 98, pp. 248-264, 2019.

[23] M. S. Altaf, A. Bouferguene, H. Liu, M. Al-Hussein, and $\mathrm{H}$. $\mathrm{Yu}$, "Integrated production planning and control system for a panelized home prefabrication facility using simulation and RFID," Automation in Construction, vol. 85, pp. 369-383, 2018.

[24] X. Li, G. Q. Shen, P. Wu, H. Fan, H. Wu, and Y. Teng, "RBLPHP: simulation of lean construction and information technologies for prefabrication housing production," Journal of Management in Engineering, vol. 34, no. 2, Article ID 04017053, 2018.

[25] S. Jang and G. Lee, "Process, productivity, and economic analyses of BIM-based multi-trade prefabrication-A case study," Automation in Construction, vol. 89, pp. 86-98, 2018.

[26] A.-Q. Gbadamosi, A.-M. Mahamadu, L. O. Oyedele et al., "Offsite construction: developing a BIM-Based optimizer for assembly," Journal of Cleaner Production, vol. 215, pp. 1180-1190, 2019.

[27] S. Abbasi, K. Taghizade, and E. Noorzai, "BIM-based combination of takt time and discrete event simulation for implementing just in time in construction scheduling under constraints," Journal of Construction Engineering and Management, vol. 146, no. 12, Article ID 04020143, 2020.

[28] G. Pasetti Monizza, C. Bendetti, and D. T. Matt, "Parametric and generative design techniques in mass-production environments as effective enablers of industry 4.0 approaches in the building industry," Automation in Construction, vol. 92, pp. 270-285, 2018.

[29] C. Sydora and E. Stroulia, "Rule-based compliance checking and generative design for building interiors using BIM," Automation in Construction, vol. 120, Article ID 103368, 2020.

[30] H. Liu, Y. Zhang, Z. Lei, H. X. Li, and S. Han, "Design for manufacturing and assembly: a bim-enabled generative framework for building panelization design," Advances in Civil Engineering, vol. 2021, Article ID 5554551, 14 pages, 2021.

[31] P. T. Nguyen, V. D. B. Huynh, and Q. L. H. T. T. Nguyen, "Evaluation factors influencing construction price index in fuzzy uncertainty environment," The Journal of Asian Finance, Economics and Business, vol. 8, pp. 195-200, 2021.

[32] S. Lee, "Determination of priority weights under multiattribute decision-making situations: AHP versus Fuzzy AHP," Journal of Construction Engineering and Management, vol. 141, no. 2, Article ID 05014015, 2015.

[33] G. Khazaeni, M. Khanzadi, and A. Afshar, "Fuzzy adaptive decision making model for selection balanced risk allocation," International Journal of Project Management, vol. 30, no. 4, pp. 511-522, 2012.

[34] H. Deng, "Multicriteria analysis with fuzzy pairwise comparison," International Journal of Approximate Reasoning, vol. 21, no. 3, pp. 215-231, 1999.

[35] J. Li and P. X. W. Zou, "Fuzzy AHP-based risk assessment methodology for PPP projects," Journal of Construction Engineering and Management, vol. 137, no. 12, pp. 1205-1209, 2011.

[36] J. Soroor, M. J. Tarokh, and M. Abedzadeh, “Automated bid ranking for decentralized coordination of construction logistics," Automation in Construction, vol. 24, pp. 111-119, 2012.

[37] A. Yazdani-Chamzini and S. H. Yakhchali, "Tunnel boring machine (TBM) selection using fuzzy multicriteria decision making methods," Tunnelling and Underground Space Technology, vol. 30, pp. 194-204, 2012.

[38] H. Liu, G. Singh, M. Lu, A. Bouferguene, and M. Al-Hussein, "BIM-based automated design and planning for boarding of light-frame residential buildings," Automation in Construction, vol. 89, pp. 235-249, 2018. 